\title{
Radical Metatarsectomy for Intractable Plantar Ulceration in Leprosy*
}

\author{
D. BHASIN \\ Senior Research Officer, \\ S.R.S. Project, \\ Tata Department of Plastic Surgery, \\ J. J. Hospital, Bombay, India \\ N. H. ANTIA \\ Professor of Plastic Surgery, \\ Tata Department of Plastic Surgery, \\ J.J. Group of Hospitals, Bombay, India
}

Recurrent plantar ulceration is the most crippling deformity of leprosy and is one of the chief factors preventing rehabilitation (Shah, 1967). Plantar ulcers usually occur on those weight-bearing areas of the foot which are deprived of the normal protective sensation as a result of nerve damage. The associated paralysis of the intrinsic muscles of the foot aggravates the condition.

Trivial trauma may result in an ulcer, but by far the most importamt mechanical factor is the shearing stress in the region of the forefoot under the metatarsal heads during locomotion (Price, 1959). Once the normal protective skin-fat cushion is damaged, recurrent breakdown of the scar under the bony pressure point is almost inevitable.

Plaster-of-Paris immobilization allows the ulcer to heal by eliminating the shearing stress and by distributing the pressure over the whole sole area. Education in the care of feet and provision of suitable footwear which distributes the pressure evenly over the whole sole often helps to prevent plantar ulceration (Price, 1964; Brand, 1966; Pavri, 1967). Local flaps have been advocated to provide better skin (Lennox, 1967), but they have limited value as they do not eliminate the chief causative factors, namely anaesthesia and pressure points.

Despite all care, recurrent plantar ulceration with the complications of cellulitis and osteomyelitis remains a major problem in a large number of patients. A below-knee amputation is neither satisfactory nor possible under the prevailing socio-economic conditions.

Hoffman in 1911 described the operation of metatarsal head resection through a plantar incision in rheumatoid arthritis. Mr H. A. Oatley, F.R.C.S., during his

* Received for publication 23 May, 1972.

This work was done in the Tata Department of Plastic Surgery, J.J. Group of Hospitals, Bombay, under Grant No. SRS-IND-43-68 from the Social and Rehabilitation Service, Department of Health, Education and Welfare, Washington, D.C. 
visit to India in December 1967, suggested and performed a more radical resection of the metatarsal bone through a dorsal approach for cases of recurrent ulceration in leprosy.

\section{Material and Results}

All patients selected for this operation had attended the "ulcer clinic" for at least one year. The ulcers had healed as the result of rest in plaster casts, but had broken down subsequently, despite the provision of protective footwear.

Radical metatarsectomy was initially performed on 5 patients with recurrent ulceration as a preliminary study. To date, 16 feet (in 13 patients) have been operated upon. Of these, 10 feet remain ulcer-free, 4 of them for 4 years after surgery. The detailed results are shown in Table 1.

\section{TABLE 1}

\begin{tabular}{lccc}
\hline Follow-up period & No. of patients & Feet operated on & Feet ulcer-free \\
\hline More than 6 months & 3 & 3 & 2 \\
6 months to 1 year & 4 & 5 & 3 \\
1 year to 2 years & 2 & 3 & 1 \\
2 years to 3 years & 1 & 1 & 0 \\
3 years to 4 years & 3 & 4 & 4 \\
& 13 & 16 & 10 \\
\hline
\end{tabular}

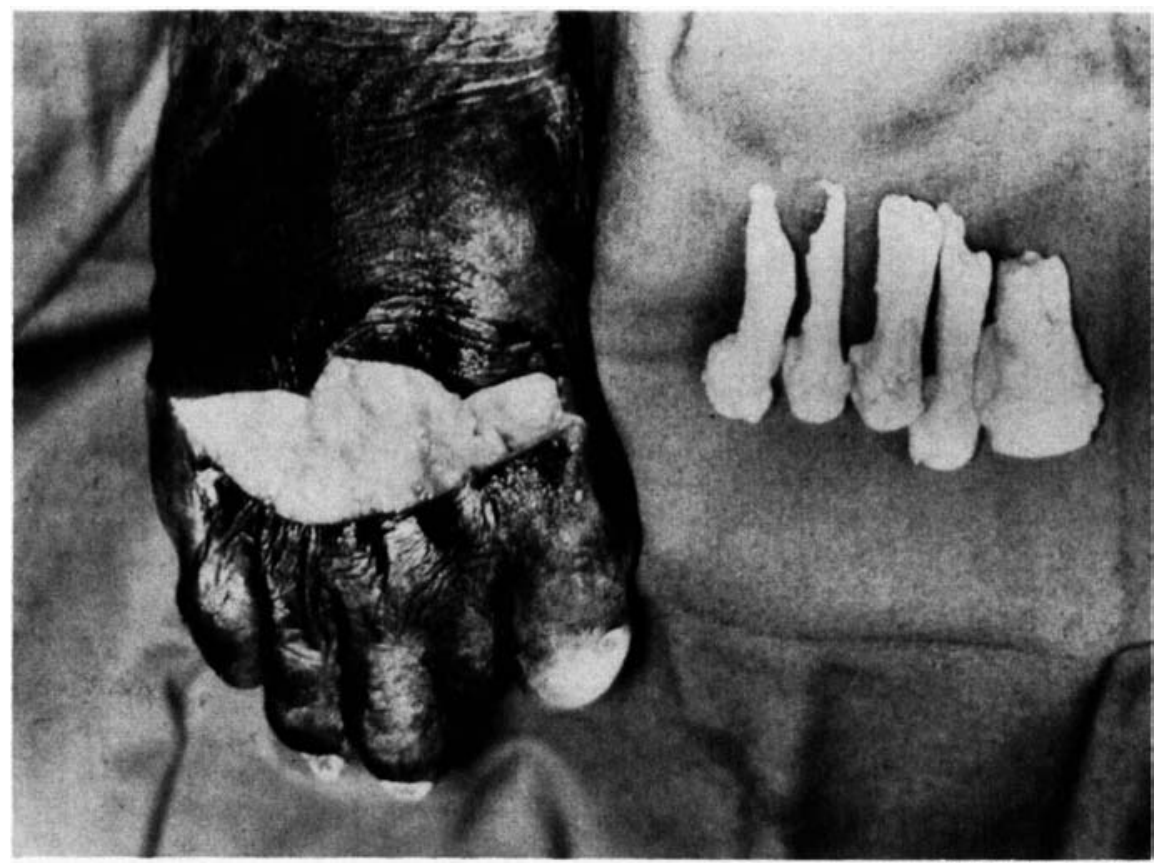

Fig. 1. Operative technique. 


\section{OPERATIVE TECHNIQUE}

The operation is performed under tourniquet. A transverse incision is made over the dorsum of the foot across the shafts of the metatarsals, care being taken to preserve a few dorsal veins. The extensor tendons to the toes are divided and the periosteum on the dorsum of the metatarsal shafts is incised longitudinally. The head and the shaft of the bone is dissected free subperiosteally and the shaft is cut close to the base of the bone. The head of the metatarsal is disarticulated from the metatarsophalangeal joint. The protruding ends of the proximal shafts are trimmed of bony spicules and bevelled to present a flat inferior surface.

The tourniquet is released, adequate haemostasis is achieved, and the soft
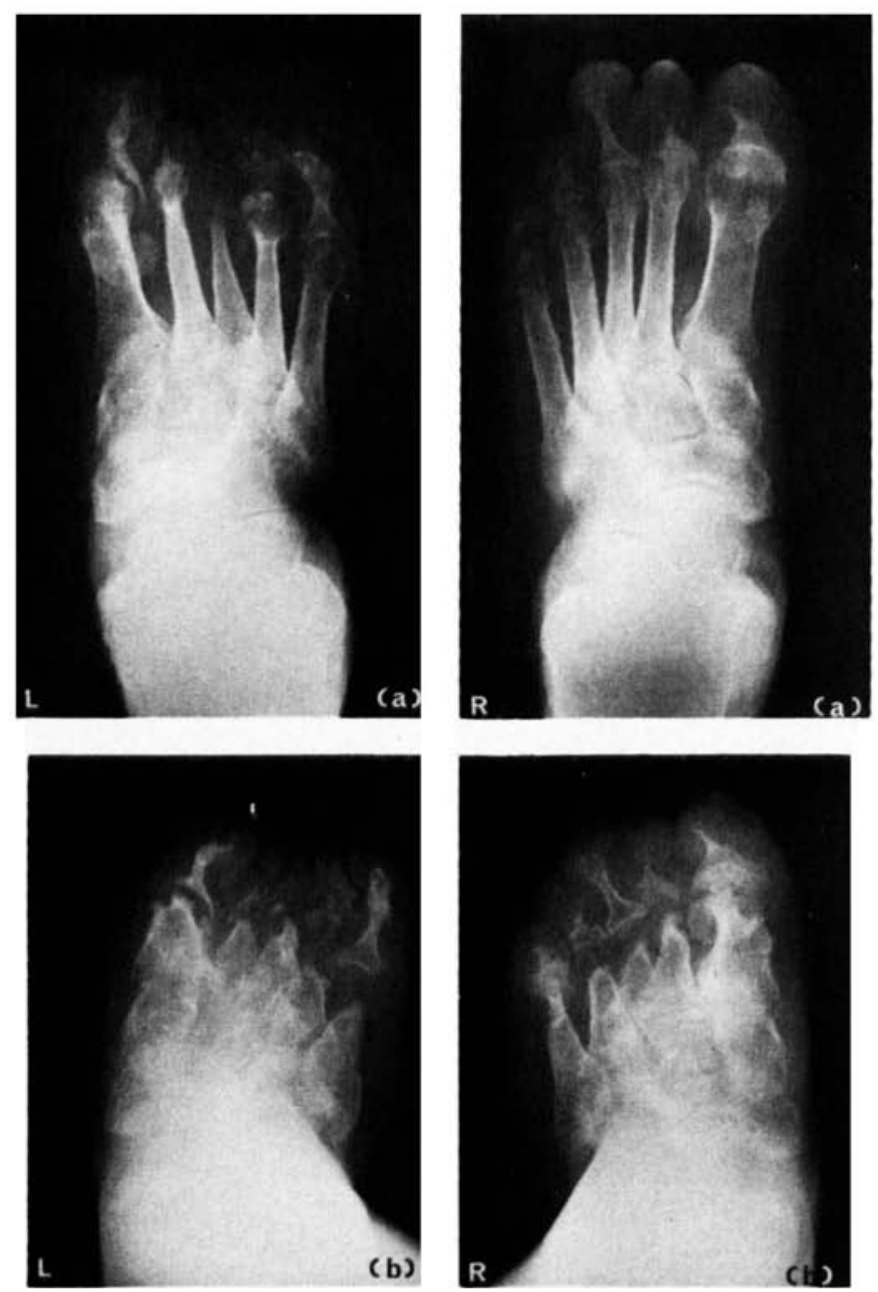

Fig. 2. (a) Pre-operative X-ray of feet (R) and (L).

(b) Post-operative X-ray of feet (R) and (L). 

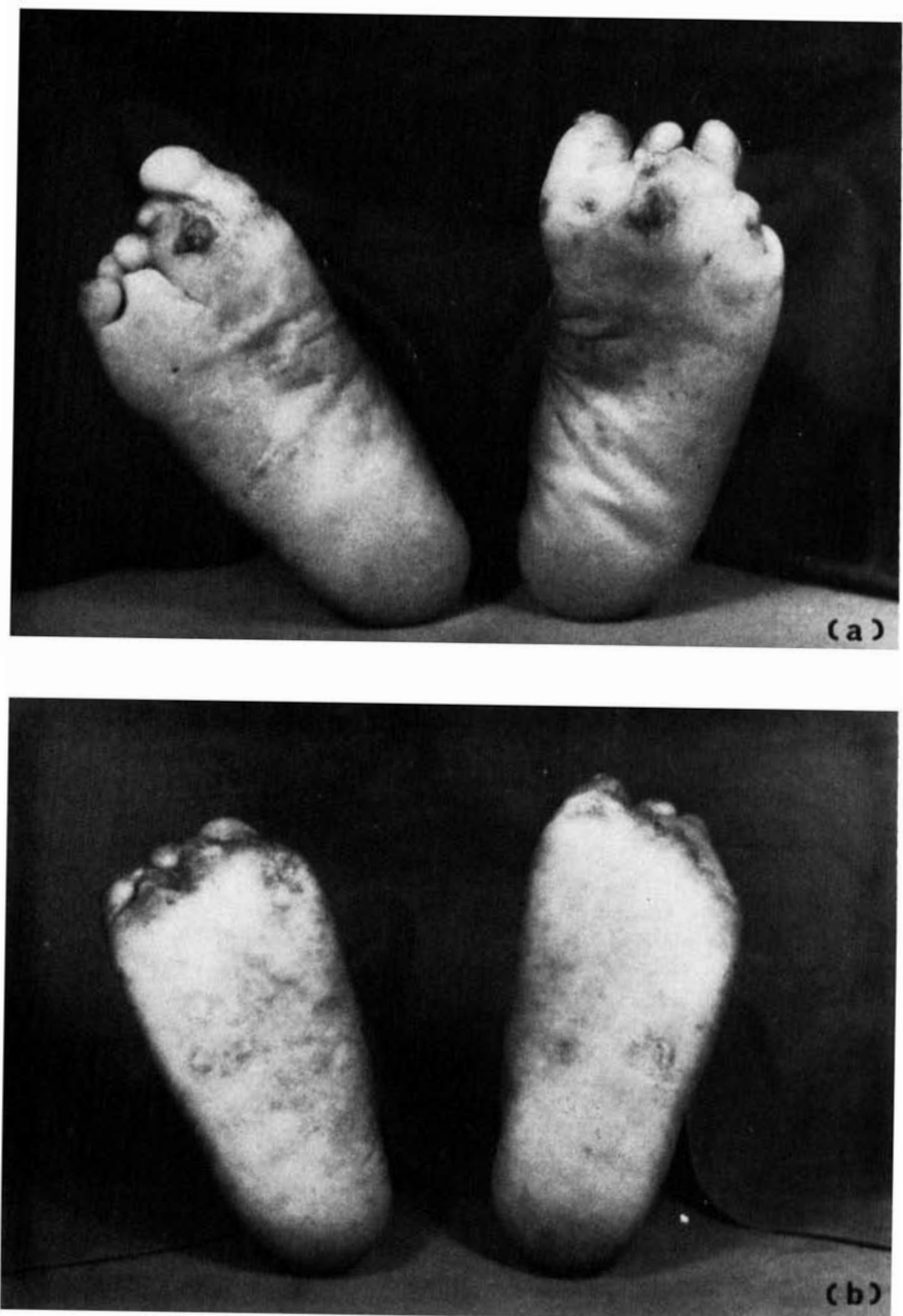

Fig. 3. A patient's feet. (a) Pre-operative (1967). (b) Post-operative (1972). 
tissues are apposed with a few plain catgut sutures. The skin wound is not sutured, but is allowed to heal by secondary intention. A below-knee Plaster-of-Paris cast is applied, with a window for dressings.

As soon as the wound on the foot heals, a shoe with a build-up of the forefoot and toe cover is provided. The shoe consists of a leather sole reinforced with a nylon sheet for rigidity. A microcellular rubber (15 shore) and/or Plastozote insole is used. A mould of the shortened foot is prepared in plaster, and the missing anterior foot is built up with sponge or Plastozote. The shoe has a closely woven toe cover and is of the same size as for a normal foot.

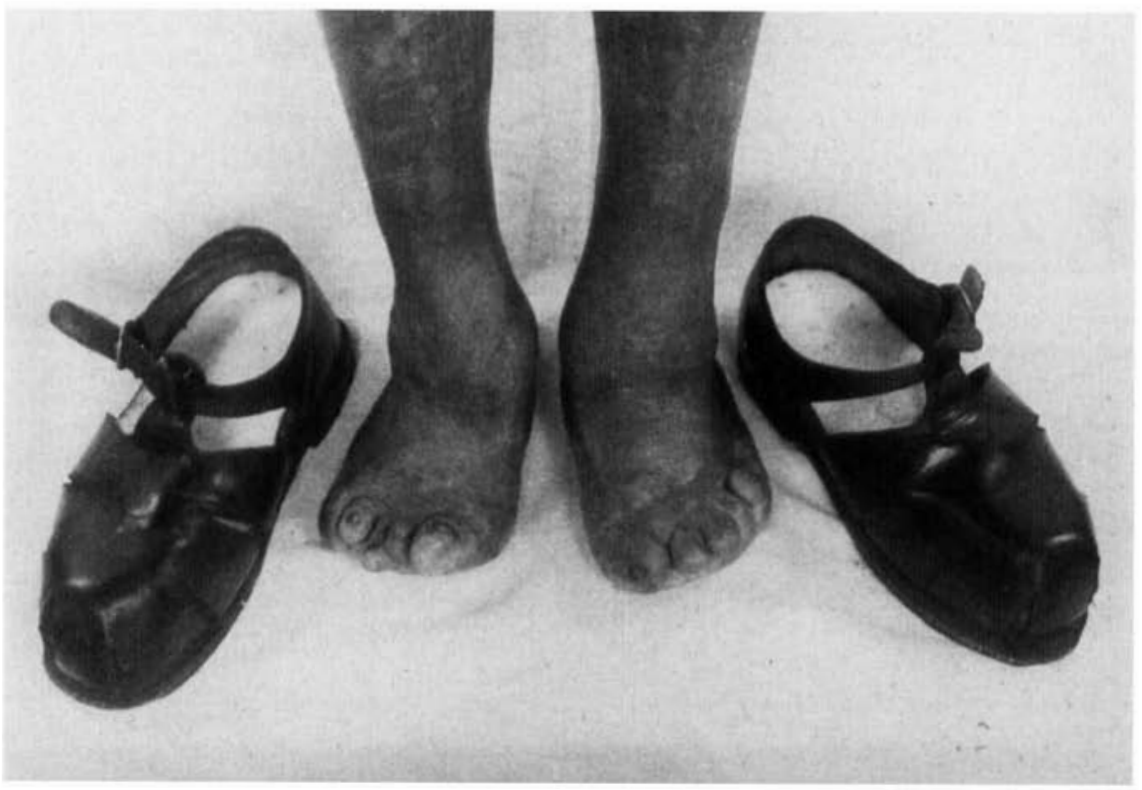

Fig. 4. Footwear.

\section{ADVANTAGES OF THE OPERATION}

(1) Total elimination of pressure points under the metatarsal heads.

(2) Bone shortening permits the soft tissue of the sole to cushion the bevelled ends of the metatarsal shafts; it also helps to heal residual ulcers.

(3) The foot is converted into a short, flat, platform by the removal of the anterior pillar of the longitudinal arch, thus distributing weight over the large and safe area of the instep.

(4) The shortening of the foot and elimination of the metatarsal heads changes normal walking. By forcing the individual to walk with short flat steps it prevents any build-up of pressure under the bony points and reduces shearing stresses on the plan tar skin.

\section{DISADVANTAGES}

Shortening of the foot is responsible for a flat, short-stepped gait, and poses difficulties in construction of suitable footwear. 


\section{Conclusion}

Of the 16 feet operated upon for recurrent ulceration 10 have remained free of pantar ulcers; 5 of these have been ulcer-free for 2 years or more, and 4 have remained ulcer-free for 4 years. These figures may not be very impressive in themselves, but they are encouraging when considered in relation to the condition of the feet operated upon.

\section{Acknowledgements}

We wish in particular to thank Mr H. A. Oatley, F.R.C.S., for suggesting this operation to us. Our thanks also to Mr H. D. Pavri, occupational therapist in the early stages of this work, to Mrs K. Naik, physiotherapist, and to Mr S. G. Kamat and Mr G. Krishnaswamy for the photographs.

\section{References}

Brand, P. W. (1966). Insensitive feet. The Leprosy Mission, London.

Pavri, H. D. (1967). Rehabilitation methods, Symposium on Leprosy,p. 163. Bombay: Bombay University Press.

Price, E. W. (1959). Studies on plantar ulcers in leprosy. Lepr. Rev. 30, 98, 180, 242.

Price, E. W. (1964). The care of the feet. In Leprosy in Theory and Practice, Cochrane \& Davey. 2nd ed., p. 510 . Bristol: John Wright \& Sons.

Shah, N. B. (1967). The socio-economic problems of leprosy patients in Greater Bombay. V.R.A. Project Report on "Rehabilitation in Leprosy". 